\title{
Optimizing the synthesis of CdS/ZnS core/shell semiconductor nanocrystals for bioimaging applications
}

\author{
Li-wei Liu*1,2, Si-yi Hu²,2, Ying Pan ${ }^{3}$, Jia-qi Zhang ${ }^{1,2}$, Yue-shu Feng ${ }^{1,2}$ \\ and Xi-he Zhang ${ }^{1,2}$
}

\section{Full Research Paper}

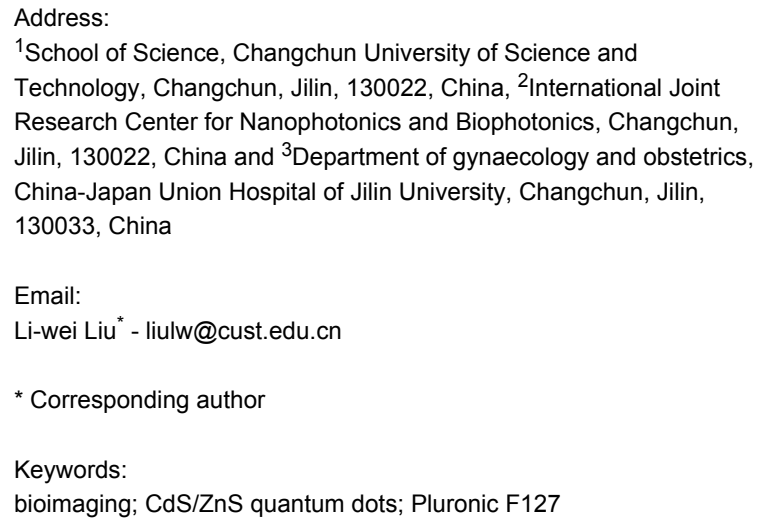

${ }^{1}$ School of Science, Changchun University of Science and Technology, Changchun, Jilin, 130022, China, ${ }^{2}$ International Joint Research Center for Nanophotonics and Biophotonics, Changchun, Jilin, 130022, China and ${ }^{3}$ Department of gynaecology and obstetrics, China-Japan Union Hospital of Jilin University, Changchun, Jilin, 130033, China

Email:

Li-wei Liu* - liulw@cust.edu.cn

* Corresponding author

Keywords:

bioimaging; CdS/ZnS quantum dots; Pluronic F127

Beilstein J. Nanotechnol. 2014, 5, 919-926. doi:10.3762/bjnano.5.105

Received: 01 April 2014

Accepted: 03 June 2014

Published: 27 June 2014

Associate Editor: J. J. Schneider

(c) 2014 Liu et al; licensee Beilstein-Institut. License and terms: see end of document.

\begin{abstract}
In this study, we report on $\mathrm{CdS} / \mathrm{ZnS}$ nanocrystals as a luminescence probe for bioimaging applications. CdS nanocrystals capped with a $\mathrm{ZnS}$ shell had enhanced luminescence intensity, stronger stability and exhibited a longer lifetime compared to uncapped CdS. The CdS/ZnS nanocrystals were stabilized in Pluronic F127 block copolymer micelles, offering an optically and colloidally stable contrast agents for in vitro and in vivo imaging. Photostability test exhibited that the ZnS protective shell not only enhances the brightness of the QDs but also improves their stability in a biological environment. An in-vivo imaging study showed that F127$\mathrm{CdS} / \mathrm{ZnS}$ micelles had strong luminescence. These results suggest that these nanoparticles have significant advantages for bioimaging applications and may offer a new direction for the early detection of cancer in humans.
\end{abstract}

\section{Introduction}

Over the past decade, the use of semiconductor nanocrystals or quantum dots (QDs) has developed remarkably due to their unique features. Compared to organic dyes, QDs have narrow emission peaks that can be systematically tuned from visible to near-infrared by manipulating their size, composition, and shape [1-7]. In addition, QDs exhibit a continuous absorption band behaviour that allows a single laser light source to excite multicolored QDs simultaneously. This is a major advantage compared with the simultaneous excitation of multiple organic dyes emitting at different wavelengths, which requires multiple light sources. All of these attractive features of QDs have made them extremely promising candidates for the new generation of optical probes for various immunoassays, multiplex imaging of cancer cells, and in vivo cancer targeting and imaging studies, 
etc. In 1998, Nie and Alivisatos were the first to report on the potential applications of QDs in biology [8,9]. There is no doubt that QDs offer a new tool for the multiplexed detection of target molecules and investigation into the intricacies of biomolecular interaction with cells [10-15]. With the development of synthesis QDs, an increasing number of QDs have been used for bioimaging and cancer detection applications.

Because the unique properties of QDs depend on their diameter, the control over the size of the ODs, their size distribution, crystallinity, and surface defects is crucial. Although they have good stability in terms of physics, the application of QDs in biology and cancer detection has been delayed due to their dispersion behaviour in aqueous solutions. It is critical to disperse QDs in water before their application by surface modification with biofunctional molecules for the purpose of bioimaging. However, for many biological applications, it is necessary to transfer the QDs into water through a capping ligand exchange [16-19]. There are many reports about the surface modification of QDs in the literature, for example, by functionalizing QDs with small molecules, e.g., sulfanylpropanoic acid, coating QDs with a silica shell, and encapsulating QDs within micelle polymer nanoparticles. Amongst the most-studied biocompatible polymer nanocarriers for in vivo studies there are Pluronic F127 triblock-copolymer micelle nanoparticles [20,21]. They can serve as a candidate for therapeutic and biomedical applications in vitro and in vivo.

A particular material for QDs, CdS, is an important direct-band semiconductor with a bandgap $\left(E_{\mathrm{g}}\right)$ of $2.42 \mathrm{eV}$. By tailoring its composition and size, or surface functionality, it is possible to enhance luminescence emission and quantum yield of these QDs. The use of a coating agent can make CdS more stable. ZnS QDs are less cytotoxic than CdTe and CdSe QDs of the same size and surface functionalization, which demonstrates that the toxicity of cadmium QDs can be reduced by encapsulating them. Furthermore, it is possible to fabricate $\mathrm{CdS} / \mathrm{ZnS}$ QDs that emit from the visible to the near-infrared (NIR) regions, and hence are suitable for bioimaging [22,23].

Several reports in the literature demonstrate the synthesis of $\mathrm{CdS}$ and CdS/ZnS QDs and their applications [24-27]. For example, Yongfen Chen et al. [28] reported the use of watersoluble luminescent CdS QDs as luminescence labels in cellular biology. Abdelhay Aboulaich et al. reported that the high photochemical stability of high luminescence-intensity $\mathrm{CdS} / \mathrm{ZnS}$ core/shell QDs are suitable for optoelectronic devices and some biological applications [29-32]. Although CdS/ZnS QDs have been proposed for the use in biological applications, no research was so far reported on their biomedical applications. Our research has developed a novel integrative strategy that produces bioconjugated CdS/ZnS QDs for the use in bioimaging. In this study, we report a rapid and straightforward method for formulating CdS/ZnS QDs, encapsulated CdS/ZnS QDs in a hydrophobic core provided by block copolymer (Pluronic F127) micelles for bioimaging. The prepared nanoparticles were carefully characterized and their stability, toxicity, and optical properties assessed. Toxicity studies revealed that the micelle-encapsulated QDs do not exhibit toxicity within the timeframe at the cellular and tissue level. To the best of our knowledge, this is the first report using CdS/ZnS QDs as luminescence probes for bioimaging.

\section{Results and Discussion Characterization of QDs}

Sizes and structure of the QDs were determined by using a JEOL JEM-100cx transmission electron microscope with an accelerating voltage of $80 \mathrm{kV}$. Transmission electron microscopy (TEM) images were taken by placing a drop of the particles in water onto a carbon film supported by a copper grid. Figure 1a shows the TEM images of organically dispersible $\mathrm{CdS} / \mathrm{ZnS}$ QDs, from which their sizes are estimated to be $4.5 \pm 1.7 \mathrm{~nm}$.

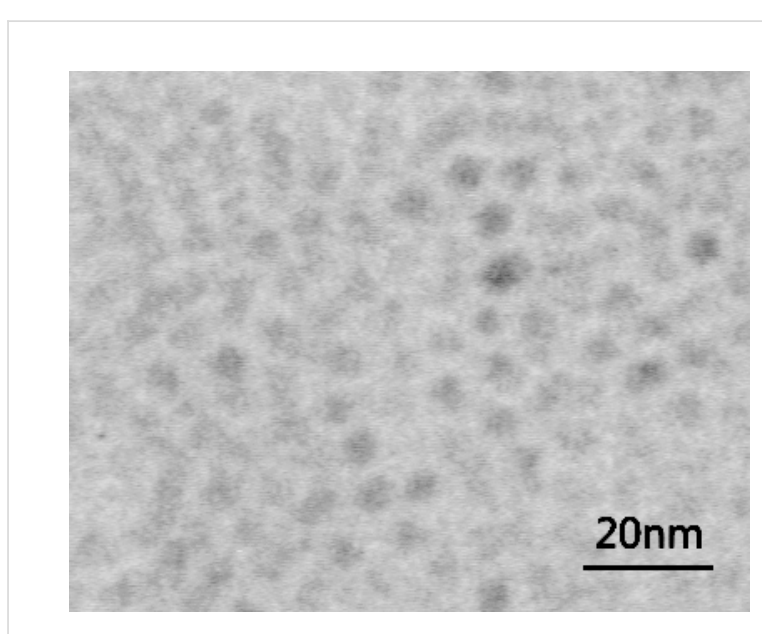

Figure 1: CdS/ZnS TEM.

The absorption spectra of QDs were collected by using a Shimadzu model 3101PC UV-vis-NIR scanning spectrophotometer over a wavelength range from 190 to $3200 \mathrm{~nm}$. The samples were measured against chloroform as a reference. Figure 2 shows the absorption, all samples were used as prepared and loaded into a quartz cell from measurements. Comparing to CdS QDs there was a redshift of about $45-55 \mathrm{~nm}$ for $\mathrm{CdS} / \mathrm{ZnS}$ QDs. This is due to the quantum confinement.

CdS/ZnS QDs were further characterized by energy dispersive $\mathrm{X}$-ray spectroscopy (EDX), as shown in Figure 3. The spectra 


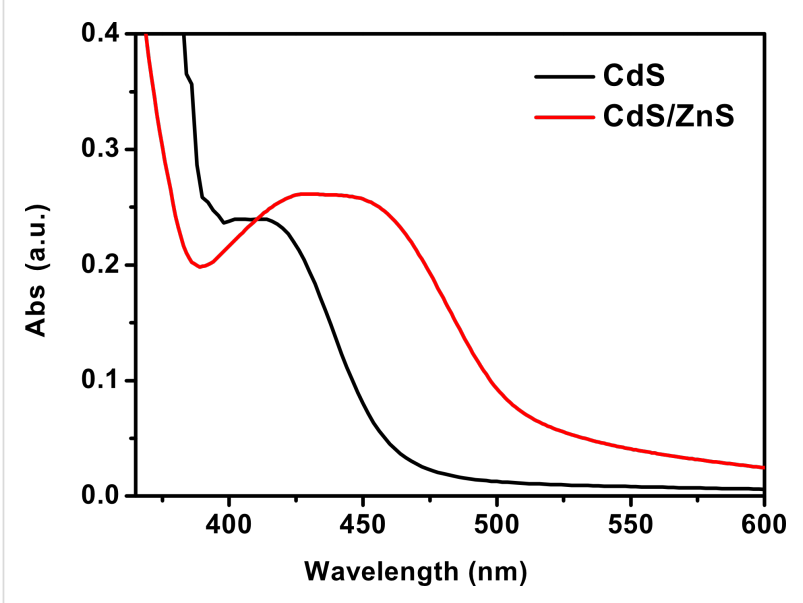

Figure 2: Absorption spectra for CdS and CdS/ZnS QDs. exhibit the composition of the CdS/ZnS QDs and indicating Cd, $\mathrm{S}$, and $\mathrm{Zn}$ as components of the $\mathrm{CdS} / \mathrm{ZnS}$ QDs.

Photoluminescence (PL) decay is an important parameter for the study of the optical and surface chemical properties of nanoparticles. A multi-exponential decay curve provides evidence for the presence of nonradiative and radiative recombination. If the electron-hole pair recombines through the radiative pathway, a photon, which is associated with the bandgap of material, is emitted. Therefore in QDs with high QY, the nonradiative recombination is relatively weak. With regard to future optical studies, we performed a lifetime test. Figure 4 shows the measured normalized PL decay curves, measured by the double exponential curve (dashed line) with an EasyLife TCSPC system excited at $377 \mathrm{~ns}$. The normalized decay curve can be well fitted by the double-exponential formula $y=A \cdot \exp \left(-t / t_{1}\right)+(1-A) \cdot \exp \left(-t / t_{2}\right)$. Based on the lifetime data,

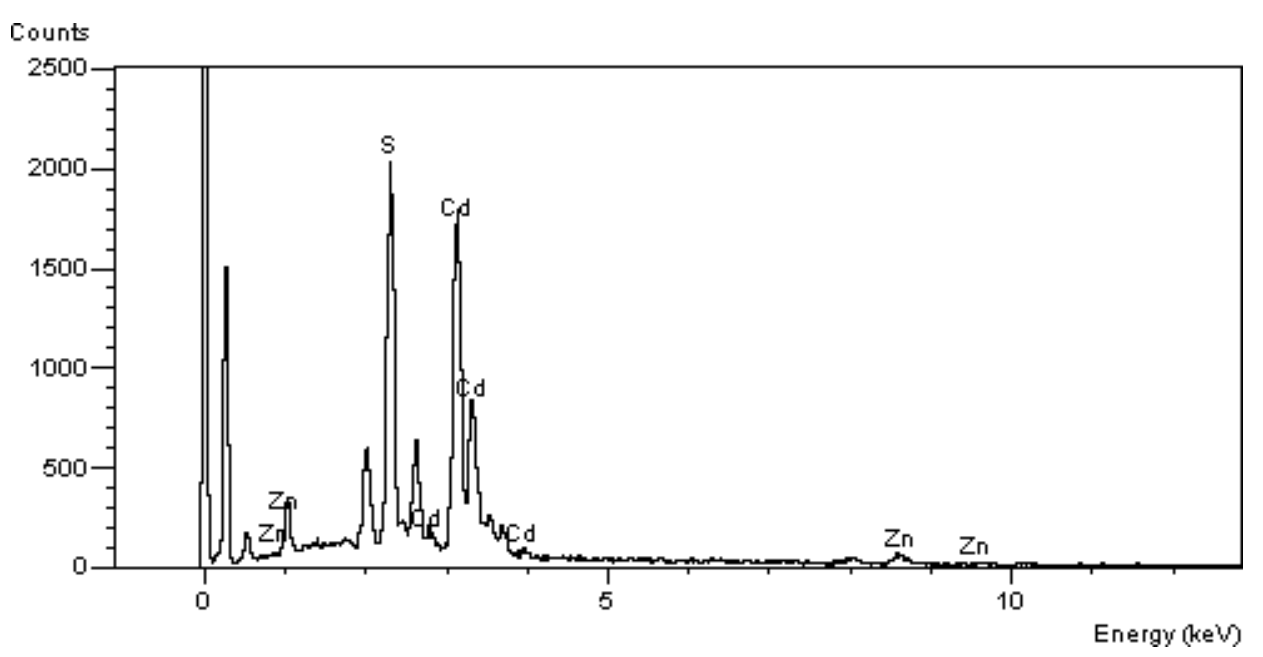

Figure 3: EDX spectra of the CdS/ZnS QDs.
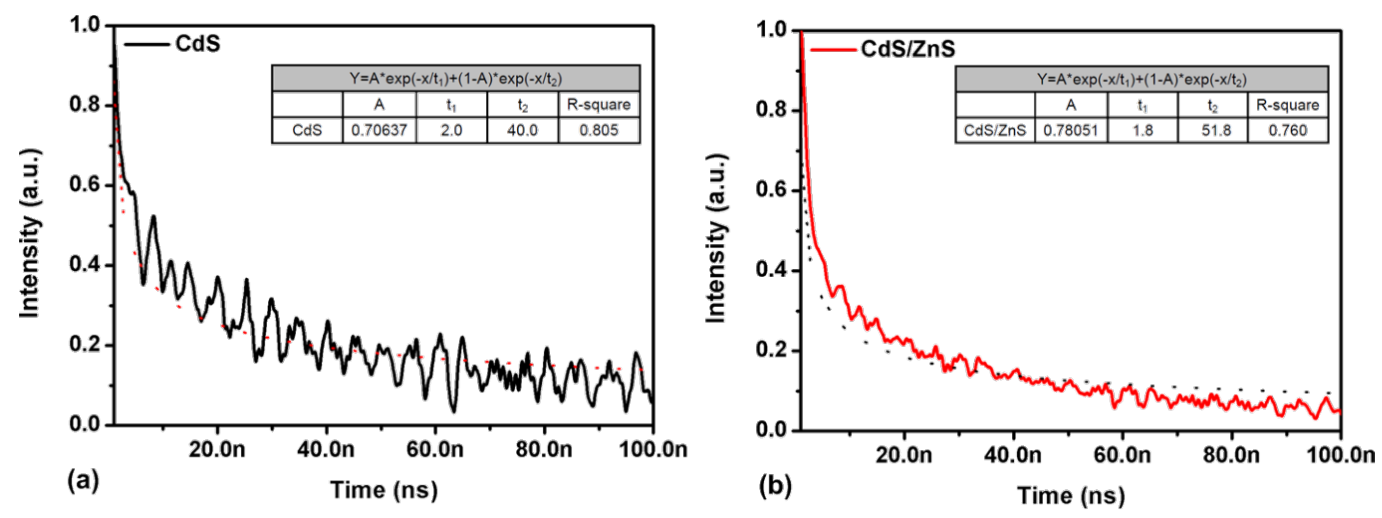

Figure 4: Fluorescence decay curves of (a) CdS and (b) CdS/ZnS QDs. 
the decay lifetime was estimated to be $50 \mathrm{~ns}$ for CdS/ZnS QDs, and $38 \mathrm{~ns}$ for CdS QDs. ZnS has a major influence on the lifetime decay profile of CdS/ZnS QDs. Trapping states are caused by surface defects located within the bandgap, which lead to the rise of nonradiative recombination.

\section{Emission spectra}

The emission spectra were collected by using a Fluorolog-3 spectrofluorometer. The excitation wavelength was set at $440 \mathrm{~nm}$ and the emission was scanned from 480 to $900 \mathrm{~nm}$. The result is shown in Figure 5 for $\mathrm{CdS} / \mathrm{ZnS}$ and F127-CdS/ZnS QDs. Both of them exhibit a red shift compared with CdS QDs. The emission spectra are broad and the full width at half maximum is noted to be around $90 \mathrm{~nm}$. This width was attributed to the wide size distribution and composite luminescence from the defect energy levels of the nanoparticles. Because the optical properties of QDs depend on the size, the absorption and emission characteristics of the QDs are closely related to the dendrimer template for preparing the QDs [33-35]. Because of the encapsulation, there is a change in the dielectric constant of the surrounding medium of the QDs, which can also be accounted for a shift of the emission wavelength.

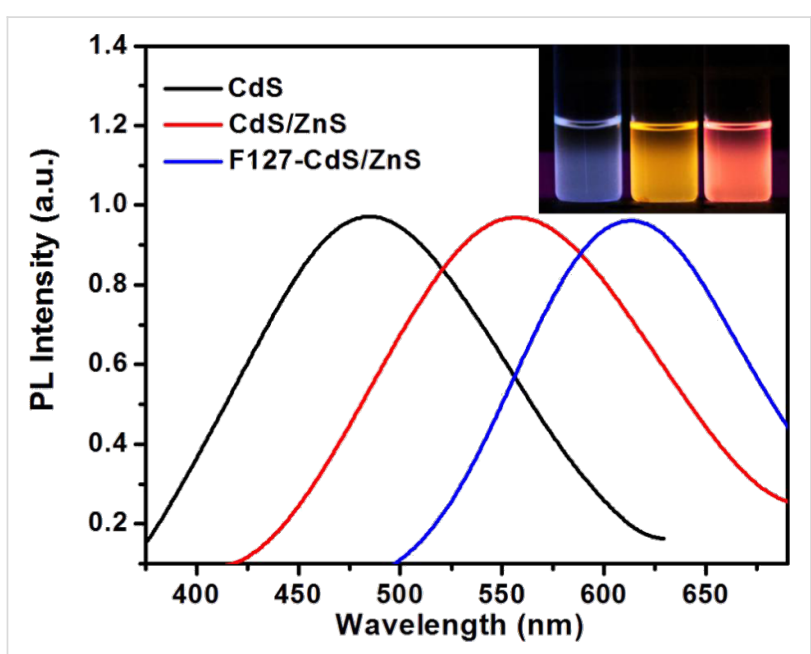

Figure 5: Emission spectrum for three samples.

Extensive research on the properties of QDs revealed that core/ shell-structured QDs are desirable due to their strongly enhanced quantum yield (QY). We also tested the QY of three samples based on Equation 1:

$$
\Phi=\Phi_{S}\left(\frac{I}{I_{\mathrm{S}}}\right)\left(\frac{A_{\mathrm{S}}}{A}\right)\left(\frac{n^{2}}{n_{\mathrm{S}}^{2}}\right)
$$

Here, $\Phi$ and $\Phi_{\mathrm{S}}$ are the QYs for the sample and the standard, $I$ (sample) and $I_{\mathrm{S}}$ (standard) are the integrated emission peak areas, $A$ (sample) and $A_{\mathrm{S}}$ (standard) are the absorption values at the excitation wavelength, and $n$ (sample) and $n_{\mathrm{S}}$ (standard) are the refractive indices of the solvent used, respectively. RG6 was used as reference. The QYs of CdS QDs, CdS/ZnS QDs and $\mathrm{F} 127-\mathrm{CdS} / \mathrm{ZnS}$ reached up to $36 \%, 42 \%$, and $65 \%$, respectively. We can see that the core/shell structured QDs showed high QYs, outstanding physical and chemical stability, this strongly enhanced QY could be attributed to the wide band gap $\mathrm{ZnS}$ shell providing surface trap states that enhance the photostability.

\section{Photostability test}

Photobleaching is an effective method for improving the bioimaging applications of nanocrystals especially for core/shell structured QDs. We carried out photostability experiments of F127-CdS/ZnS irradiated by continuous-wave (CW) laser with a wavelength of $447 \mathrm{~nm}$ and power density of $0.5 \mathrm{~W} / \mathrm{cm}^{2}$. PL tests with different irradiate times were carried out. As Figure 6, Figure 7 and Figure 8 show, the results indicate that photobleaching has occurred. The experimental results revealed that F127-CdS/ZnS exhibits excellent photostability compared to the CdS QDs. CdS/ZnS QDs have almost the same photostability as F127-CdS/ZnS, and the PL intensity of F127-CdS/ZnS and $\mathrm{CdS} / \mathrm{ZnS}$ QDs change less significantly after laser irradiation. This indicates that the bioconjugation with F127 did not affect the stability of the CdS/ZnS QDs. CdS and ZnS are group II-VI semiconductors with a similar crystalline structure and a lattice mismatch of $6.4 \%$. As $\mathrm{ZnS}$ is a phosphor material with a high bandgap energy of $3.66 \mathrm{eV}$, the use of $\mathrm{ZnS}$ leads to enhanced stability and luminescence intensity. The $\mathrm{ZnS}$ protective shell not only enhances the brightness of the QDs but also improves their stability in a biological environment. This study provides a useful synthetic route for producing water-dispersible nanocrystals that should easily be applicable in biology.

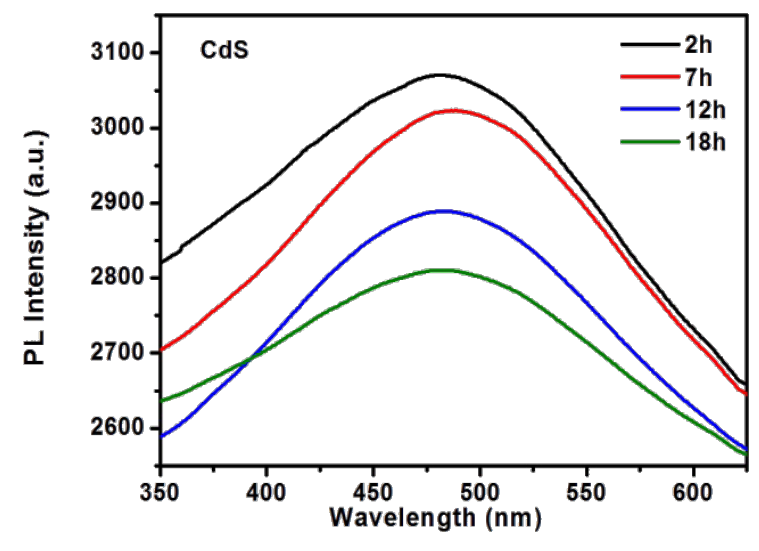

Figure 6: CdS PL spectra for photobleaching. 


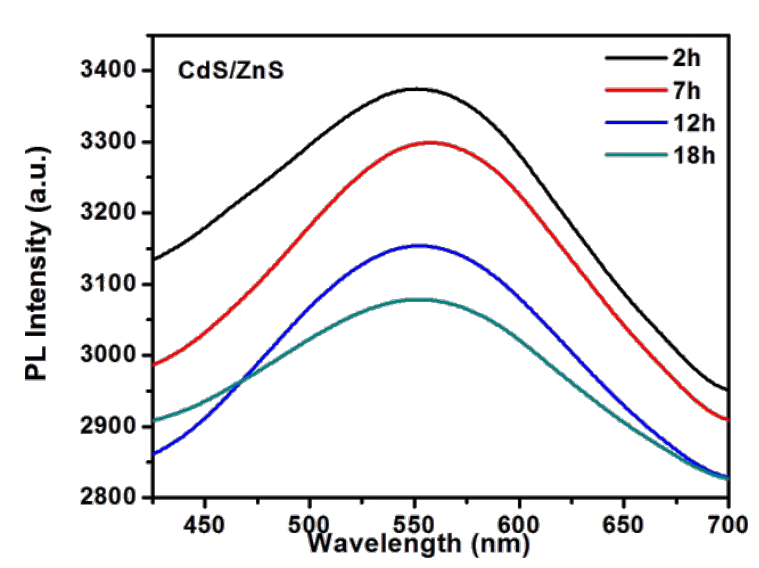

Figure 7: CdS/ZnS PL spectra for photobleaching.

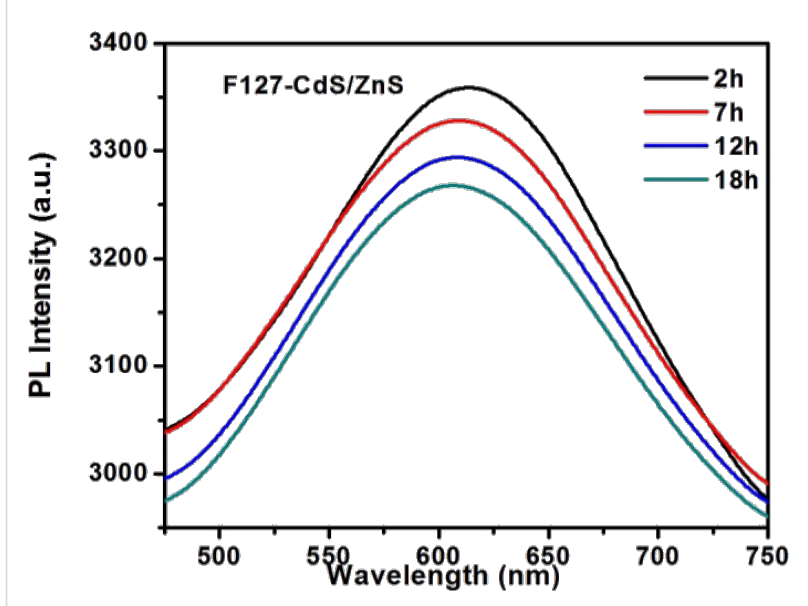

Figure 8: F127-CdS/ZnS PL spectra for photobleaching.

\section{Effect of $\mathrm{pH}$ on the hydrodynamic diameter of the QDs}

The dynamic light scattering (DLS) technique was used to measure the hydrodynamic diameter profile of the micelleencapsulated nanocrystals. For the purposes of the DLS analysis, the thickness of the adsorbed polymer layer was determined according to Equation 2 [36]:

$$
\delta=\frac{d_{\mathrm{a}}-d_{0}}{2}
$$

where $\delta$ is the width of the polymer layer, $d_{\mathrm{a}}$ is the hydrodynamic size after polymer adsorption and $d_{0}$ is the hydrodynamic size of the bare nanospheres. However, the bare nanospheres were not stable. From this equation, we determined that the dispersion in water and the $\mathrm{pH}$ value can affect their stability. We used DLS as an accurate approach to monitor the colloidal stability of F127-CdS/ZnS micelles. The DLS samples were diluted in HPLC water (1:30). Then, we investigated the formulation of the micelle-encapsulated nanoparticles under various $\mathrm{pH}$ values, testing the stability of the F127-CdS/ZnS QDs. The variation of the hydrodynamic diameter under different $\mathrm{pH}$ values is shown in Figure 9. The result suggests that their stability is not affected by $\mathrm{pH}$ values.

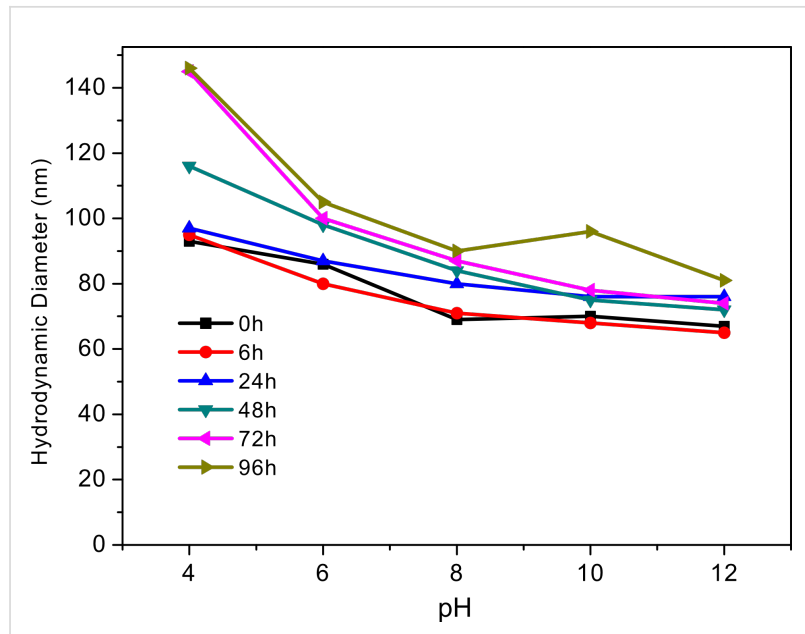

Figure 9: Hydrodynamic diameter measured by DLS for F127-CdS/ ZnS QDs at different $\mathrm{pH}$ values.

\section{Cell imaging and viability studies}

For in vitro studies, a cell viability (MTS) assay was carried out for F127-CdS/ZnS QDs. As shown in Figure 10, we tested the cell viability of Panc-1 cells, treating them with various concentrations of ternary nanocrystal formulations for $48 \mathrm{~h}$. The cell viability remained at $84 \%$ even at a concentration as high as $500 \mu \mathrm{g} / \mathrm{mL}$. This experiment demonstrates the minimal cytotoxicity associated with these nanoparticle formulations.

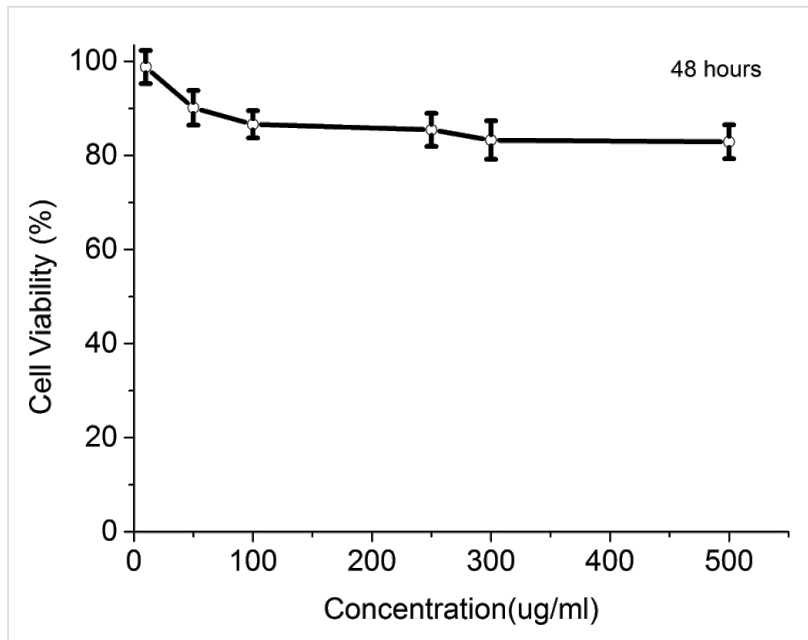

Figure 10: Viability of Panc-1 cells after $48 \mathrm{~h}$ of treatment in the presence of F127-CdS/ZnS QDs. 
For the bioimaging study, it is well known the cell membrane folate receptor is a potential molecular target for tumor-selective drug delivery, and the folate conjugates can be used to target pancreatic cancer. In our study, in vitro confocal microscopy studies were performed to re-confirm the uptake of F127-CdS/ZnS QDs bioconjugates in Panc-1 cells. Panc-1 cells were treated with F127-CdS/ZnS QDs for $2 \mathrm{~h}$. Subsequently, the cells were rinsed with a PBS buffer to remove free nanocrystals and imaged by using confocal microscopy. Figure 11 shows robust cellular uptakes of the ternary nanocrystal samples. The red singnal is from F127-CdS/ZnS QDs, and background fluorescence and autofluorescence from the cells have been successfully suppressed. We can see that there is no damage to the cells, indicating the low toxicity of the formulated nanoparticles.

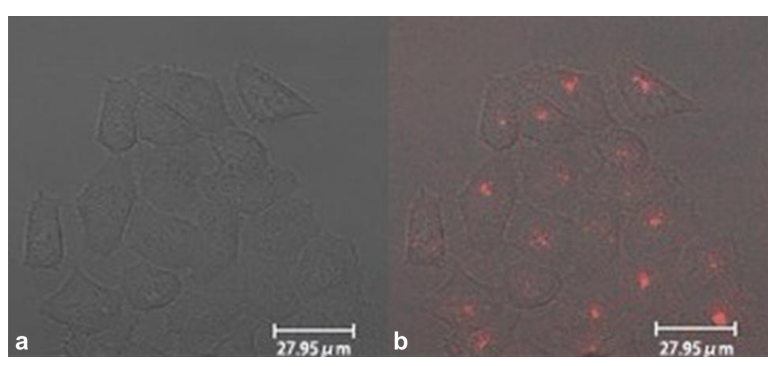

Figure 11: Confocal microscopic images of Panc-1cell treated with micelle encapsulated CdS /ZnS (a) transmission image, (b) overlay image.

\section{Animal studies}

Five-week-old nude female mice were purchased from the experimental animal center of Jilin University. The animal housing area was maintained at $24{ }^{\circ} \mathrm{C}$ with a $12 \mathrm{~h} \mathrm{light/dark}$ cycle. The animals were fed ad libitum with water and standard laboratory chow. The F127-CdS/ZnS micelles were injected into the nude mice subcutaneously, and the imaging was retrieved with a Maestro optical system with spectrally optimized lens system and a $470 \mathrm{~nm}$ laser. Images were recorded with a scientific-grade megapixel CCD sensor. The result is shown in Figure 12. Figure 12a is the bright field image, and Figure $12 \mathrm{~b}$ is the overlay image. We found that there was a bright emission where F127-CdS/ZnS micelles were injected. In addition, we determined that the signal of the QDs (red) can be separated from the autofluorescence background (green). This in vivo imaging indicated the great potential of $470 \mathrm{~nm}$ laser excitation for autofluorescence-free QDs-based animal imaging. Further studies involving a systemic administration of the nanoparticles via the intravenous route and their subsequent studies of the biodistribution are required to gather information about the in vivo toxicity and the excretion from the animal body.

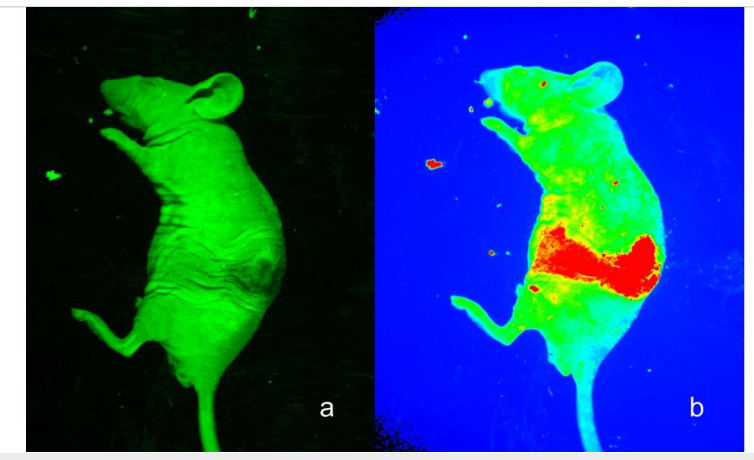

Figure 12: In vivo whole body imaging of nude mouse injected with F127-CdS/ZnS QDs, (a) transmission image, (b) luminescence imaging.

\section{Conclusion}

In summary, we have prepared nanoparticles as excellent nanoprobes for bioimaging applications. CdS/ZnS QDs encapsulated in biocompatible amphiphilic Pluronic F127 have a good photo-stability and were successfully used for in vitro and in vivo studies. In addition, from our study of cell viability, the prepared ternary nanocrystals were shown to have a low cytotoxicity. Given their biocompatibility and the high efficiency in relation to targeted delivery, these nanoparticles have great potential to serve as a new generation of multifunction agents for clinic diagnosis and treatment.

\section{Experimental \\ Materials}

Cadmium oxide (CdO, 99.9+\%), oleic acid (OA, 99\%), sulfur (S, 99\%), zinc chloride anhydrous $\left(\mathrm{ZnCl}_{2}, 98+\%\right)$, sodium diethyldithiocarbamate trihydrate (Na(DDTC), 98\%), were purchased from Alfa Aesar. 1-Octadecene (ODE, 90\%), oleylamine (OAm, $>50.0 \%$ ), Pluronic F127 were purchased from Sigma-Aldrich. Ethanol (99.8\%) and chloroform (99.0+\%) were purchased from Acros Organics. All chemical materials were used as received without further purification. HPLC grade water was used in all the experiments.

\section{Preparation of $\mathrm{Zn}(\mathrm{DDTC})$ solution}

Typically, $2 \mathrm{mmol}$ each of $\mathrm{Na}(\mathrm{DDTC})$ and $\mathrm{ZnCl}_{2}$ were dissolved in $20 \mathrm{~mL}$ of ultrapure water, respectively. The $\mathrm{Zn}$ (DDTC) precursor solution was prepared by mixing $\mathrm{Na}$ (DDTC) and $\mathrm{ZnCl}_{2}$ solution in a $100 \mathrm{~mL}$ beaker, then stirred for $2 \mathrm{~h}$ to obtain the milky solution. It was then dried in a vacuum drying oven at $60{ }^{\circ} \mathrm{C}$. Finally, $1 \mathrm{mmol}$ of $\mathrm{Zn}$ (DDTC) was added to a flask with $10 \mathrm{~mL}$ of OAm, and sonicated for 20 min under $\mathrm{N}_{2}$ flow.

\section{Preparation of sulfur solution}

The sulfur solution was prepared by reducing $1 \mathrm{mmol}$ of sulfur powder with $5 \mathrm{~mL}$ of OAm in a flask. After degassing at room 
temperature for $10 \mathrm{~min}$, the solution was heated to $100{ }^{\circ} \mathrm{C}$ under $\mathrm{N}_{2}$ flow, and the temperature was maintained for $10 \mathrm{~min}$. The resulting sulfur solution was then cooled to room temperature for further application.

\section{Synthesis of CdS/ZnS core/shell QDs}

Synthesis of CdS/ZnS was based on a procedure reported previously [37]. The Cd solution was prepared by reducing $0.4 \mathrm{~mol}$ of $\mathrm{CdO}$ with $1 \mathrm{~mL}$ of $\mathrm{OA}$ and $15 \mathrm{~mL}$ of ODE in a $100 \mathrm{~mL}$ three-necked flask at room temperature. The mixture was heated to $260{ }^{\circ} \mathrm{C}$, maintained at $260{ }^{\circ} \mathrm{C}$ and then stirred for 10 min under $\mathrm{N}_{2}$ flow. The flask was sealed and subsequently $2 \mathrm{~mL}$ of sulfur solution was injected to the mixture and the temperature was maintained at $240{ }^{\circ} \mathrm{C}$ for $5 \mathrm{~min}$, after that the mixture was cooled to $50{ }^{\circ} \mathrm{C}$. Then $0.5 \mathrm{~mL}$ of $\mathrm{Zn}$ (DDTC) solution was added to the mixture and the mixture was heated to $180^{\circ} \mathrm{C}$, maintained at $180^{\circ} \mathrm{C}$ for $20 \mathrm{~min}$. Finally, the mixture was cooled to room temperature, and separated by the addition of $20 \mathrm{~mL}$ of ethanol and by two cycles of centrifugation.

\section{Preparation of water dispersible micelle- encapsulated QDs}

$300 \mu \mathrm{L}$ of $\mathrm{CdS} / \mathrm{ZnS}$ stock solution in chloroform $(2 \mathrm{mg} / \mathrm{mL})$ was mixed with $600 \mu \mathrm{L}$ of $\mathrm{F} 127$ solution $(10 \mathrm{mg} / \mathrm{mL}$ in chloroform) by gentle stirring for $5 \mathrm{~min}$. The mixture was then evaporated and dried using a roto-evaporator. The residue film was heated to $70-80{ }^{\circ} \mathrm{C}$, and $0.5 \mathrm{~mL}$ of water was added to obtain an optically clear suspension. The micelle-encapsulated QDs, F127-CdS/ZnS, were purified by centrifugation and then redispersed in water for further use. F127 is known to stabilize nanospheres and prolong their circulation time in vivo. In this experiment, F127 was used to modify the surface of the CdS/ ZnS QDs

\section{Preparation of in vitro cell imaging}

Panc-1 cells were maintained in Dulbecco's modified Eagle's medium (DMEM, Sigma-Aldrich) supplemented with $10 \%$ fetal bovine serum (FBS, Hyclone) and cultured at $37^{\circ} \mathrm{C}$ in a humidified atmosphere with $5 \% \mathrm{CO}_{2}$. For cell imaging, cells were treated with F127-CdS/ZnS micelles formulations for $2 \mathrm{~h}$. The cells were then washed with PBS for three times and imaged using a Leica confocal microscopy system (TCS SP2). For the cell viability assays, about 5000 cells were dispensed into each well of a 96-well flat-bottom Microtiter plate and cultured overnight. Eight sets were treated with different concentrations of QDs formulations and one set treated with PBS buffer was regarded as the non-treated control. The cells were subsequently incubated for $48 \mathrm{~h}$ before the assay. Assays were performed in triplicate and the results were averaged.

\section{Acknowledgements}

This work was supported by the National Natural Science Foundation of China (No. 11204020).

\section{References}

1. Prasad, P. N. Introduction to Nanomedicine and Nanobioengineering; John Wiley \& Sons: Hoboken, NJ, USA, 2012.

2. Prasad, P. N. Nanotechnology for Biophotonics: Bionanophotonics. Introduction to Bionanophotonics; John Wiley \& Sons: Hoboken, NJ, USA, 2004; pp 520-544. doi:10.1002/0471465380.ch15

3. Weissleder, R.; Tung, C.-H.; Mahmood, U.; Bogdanov, A., Jr. Nat. Biotechnol. 1999, 17, 375-378. doi:10.1038/7933

4. Ntziachristos, V.; Bremer, C.; Weissleder, R. Eur. Radiol. 2003, 13, 195-208. doi:10.1007/s00330-002-1524-x

5. Weissleder, R.; Ntziachristos, V. Nat. Med. 2003, 9, 123-128. doi:10.1038/nm0103-123

6. Sharma, P.; Brown, S.; Walter, G.; Santra, S.; Moudgil, B. Adv. Colloid Interface Sci. 2006, 123-126, 471-485. doi:10.1016/j.cis.2006.05.026

7. Shah, C. P.; Rath, M.; Kumar, M.; Bajaj, P. N. Beilstein J. Nanotechnol. 2010, 1, 119-127. doi:10.3762/bjnano.1.14

8. Bruchez, M., Jr.; Moronne, M.; Gin, P.; Weiss, S.; Alivisatos, A. P. Science 1998, 281, 2013-2016. doi:10.1126/science.281.5385.2013

9. Chan, W. C. W.; Nie, S. M. Science 1998, 281, 2016-2018. doi:10.1126/science.281.5385.2016

10. Reimann, S. M.; Manninen, M. Rev. Mod. Phys. 2002, 74, 1283-1342. doi:10.1103/RevModPhys.74.1283

11. Michalet, X.; Pinaud, F. F.; Bentolila, L. A.; Tsay, J. M.; Doose, S.; Li, J. J.; Sundaresan, G.; Wu, A. M.; Gambhir, S. S.; Weiss, S. Science 2005, 307, 538-544. doi:10.1126/science.1104274

12. Zhou, M.; Ghosh, I. Biopolymers 2007, 88, 325-339. doi:10.1002/bip.20655

13. Gokarna, A.; Jin, L.-H.; Hwang, J. S.; Cho, Y.-H.; Lim, Y. T.; Chung, B. H.; Youn, S. H.; Choi, D. S.; Lim, J. H. Proteomics 2008, 8, 1809-1818. doi:10.1002/pmic.200701072

14. Weng, K. C.; Noble, C. O.; Papahadjopoulos-Sternberg, B.; Chen, F. F.; Drummond, D. C.; Kirpotin, D. B.; Wang, D.; Hom, Y. K.; Hann, B.; Park, J. W. Nano Lett. 2008, 8, 2851-2857. doi:10.1021/nl801488u

15. Marchal, F.; Pic, E.; Pons, T.; Dubertret, B.; Bolotine, L.; Guillemin, F. Bull. Cancer 2008, 95, 1149-1153. doi:10.1684/bdc.2008.0757

16. Batrakova, E. V.; Kabanov, A. V. J. Controlled Release 2008, 130 , 98-106. doi:10.1016/j.jconrel.2008.04.013

17. Ding, H.; Yong, K.-T.; Roy, I.; Pudavar, H. E.; Law, W. C.; Bergey, E. J.; Prasad, P. N. J. Phys. Chem. C 2007, 111, 12552-12557. doi:10.1021/jp0733419

18. Yong, K.-T.; Ding, H.; Roy, I.; Law, W.-C.; Bergey, E. J.; Maitra, A.; Prasad, P. N. ACS Nano 2009, 3, 502-510. doi:10.1021/nn8008933

19. Lu, Y. J.; Sega, E.; Leamon, C. P.; Low, P. S. Adv. Drug Delivery Rev. 2004, 56, 1161-1176. doi:10.1016/j.addr.2004.01.009

20. Low, P. S.; Henne, W. A.; Doorneweerd, D. D. Acc. Chem. Res. 2008, 41, 120-129. doi:10.1021/ar7000815

21. Pan, D.; Turner, J. L.; Wooley, K. L. Chem. Commun. 2003, 2400-2401. doi:10.1039/b307878g

22. Cho, S. J.; Maysinger, D.; Jain, M.; Röder, B.; Hackbarth, S.; Winnik, F. M. Langmuir 2007, 23, 1974-1980. doi:10.1021/la060093j

23. Li, H.; Li, M.; Shih, W. Y.; Lelkes, P. I.; Shih, W.-H. J. Nanosci. Nanotechnol. 2011, 11, 3543-3551. doi:10.1166/jnn.2011.3803 
24. Chen, D.; Zhao, F.; Qi, H.; Rutherford, M.; Peng, X. Chem. Mater. 2010, 22, 1437-1444. doi:10.1021/cm902516f

25. Chen, H.-Y.; Maiti, S.; Son, D. H. ACS Nano 2012, 6, 583-591. doi:10.1021/nn204452e

26. Smyntyna, V.; Semenenko, B.; Skobeeva, V.; Malushin, N. Beilstein J. Nanotechnol. 2014, 5, 355-359. doi:10.3762/bjnano.5.40

27. Yang, Y.; Chen, O.; Angerhofer, A.; Cao, Y. C. J. Am. Chem. Soc. 2008, 130, 15649-15661. doi:10.1021/ja805736k

28. Chen, Y.; Rosenzweig, Z. Anal. Chem. 2002, 74, 5132-5138. doi:10.1021/ac0258251

29. Aboulaich, A.; Billaud, D.; Abyan, M.; Balan, L.; Gaumet, J.-J.; Medjadhi, G.; Ghanbaja, J.; Schneider, R. ACS Appl. Mater. Interfaces 2012, 4, 2561-2569. doi:10.1021/am300232z

30. Takahashi, T.; Kudo, A.; Kuwabata, S.; Ishikawa, A.; Ishihara, H.; Tsuboi, Y.; Torimoto, T. J. Phys. Chem. C 2013, 117, 2511-2520. doi:10.1021/jp3064257

31. Mao, B.; Chuang, C.-H.; Lu, F.; Sang, L.; Zhu, J.; Burda, C. J. Phys. Chem. C 2013, 117, 648-656. doi:10.1021/jp309202g

32. Connelly, S.; Choi, S.; Johnson, S. M.; Kelly, J. W.; Wilson, I. A. Curr. Opin. Struct. Biol. 2010, 20, 54-62. doi:10.1016/j.sbi.2009.12.009

33. Jin, T.; Fujii, F.; Yamada, E.; Nodasaka, Y.; Kinjo, M. J. Am. Chem. Soc. 2006, 128, 9288-9289. doi:10.1021/ja062021k

34. Takagahara, T. Phys. Rev. B 1993, 47, 4569-4585. doi:10.1103/PhysRevB.47.4569

35. Duan, H.; Jiang, Y.; Zhang, Y.; Sun, D.; Liu, C.; Huang, J.; Lan, X.; Zhou, H.; Chen, L.; Zhong, H. Nanotechnology 2013, 24, 285201. doi:10.1088/0957-4484/24/28/285201

36. Besheer, A.; Vogel, J.; Glanz, D.; Kressler, J.; Groth, T.; Mäder, K Mol. Pharmaceutics 2009, 6, 407-415. doi:10.1021/mp800119h

37. Liu, X.; Jiang, Y.; Lan, X.; Zhang, Y.; Li, S.; Li, J.; Han, T.; Wang, B.; Zhong, H. Mater. Chem. Phys. 2011, 130, 909-914. doi:10.1016/j.matchemphys.2011.08.009

\section{License and Terms}

This is an Open Access article under the terms of the Creative Commons Attribution License (http://creativecommons.org/licenses/by/2.0), which permits unrestricted use, distribution, and reproduction in any medium, provided the original work is properly cited.

The license is subject to the Beilstein Journal of Nanotechnology terms and conditions: (http://www.beilstein-journals.org/bjnano)

The definitive version of this article is the electronic one which can be found at: doi:10.3762/bjnano.5.105 